\title{
Research
}

\section{A method for measuring continuity of care in day-to-day general practice:}

\author{
a quantitative analysis of appointment data
}

\begin{abstract}
\section{Background}

Despite patient preference and many known benefits, continuity of care is in decline in general practice. The most common method of measuring continuity is the Usual Provider of Care (UPC) index. This requires a number of appointments per patient and a relatively long timeframe for accuracy, reducing its applicability for day-to-day performance management.
\end{abstract}

\section{Aim}

To describe the St Leonard's Index of Continuity of Care (SLICC) for measuring GP continuity regularly, and demonstrate how it has been used in service in general practice.

\section{Design and setting}

Analysis of appointment audit data from 2016-2017 in a general practice with 8823-9409 patients and seven part-time partners, in Exeter, UK.

\section{Method}

The percentage of face-to-face appointments for patients on each doctor's list, with the patient's personal doctor (the SLICC), was calculated monthly. The SLICC for different demographic groupings of patients (for example, sex and frequency of attendance) was compared. The UPC index over the 2 years was also calculated, allowing comparisons between indices.

\section{Results}

In the 2-year study period, there were 35622 GP face-to-face appointments; 1.96 per patient per year. Overall, 51.7\% 195\% confidence interval $=51.2$ to 52.2 ) of GP appointments were with the patients' personal doctor. Patients aged $\geq 65$ years had a higher level of continuity with $64.9 \%$ of appointments being with their personal doctor. The mean whole-practice UPC score was 0.61 (standard deviation 0.23), with 'usual provider' being the personal GP for $52.8 \%$ and a trainee or locum for $8.1 \%$ of patients.

\section{Conclusion}

This method could provide working GPs with a simple way to track continuity of care and inform practice management and decision making.

\section{Keywords}

continuity of patient care; family practice general practice; measurement.

\section{INTRODUCTION}

Continuity of care is defined as a patient and doctor seeing each other repeatedly and is a proxy for the doctor-patient relationship. ${ }^{1}$ As the number of consultations a doctor and patient have with each other increases, so does the responsibility that the doctor feels for the patient ${ }^{2}$ and the trust the patient feels for the doctor. ${ }^{3}$ Continuity of care in general practice has been shown in numerous studies to be associated with many positive outcomes for patients, doctors, 4,5 and health systems. ${ }^{6}$ These include increased satisfaction in patients, ${ }^{7.8}$ better adherence by patients to medical advice, 9,10 better uptake of personal preventive medicine, ${ }^{11,12}$ and lower use of hospital outpatients and inpatients..$^{13,14}$ In 2018, a systematic review found that better continuity of doctor care is associated with lower mortality. ${ }^{15}$ In a general practice using the personal list system, ${ }^{16}$ a patient is more likely to have continuity of care with their own doctor ${ }^{17,18}$ and be more satisfied. ${ }^{19}$ Conversely, there have been reports of large, combined list practices where continuity is poorer, ${ }_{1}^{14}$ having delayed diagnosis of cancer ${ }^{20}$ and poor care for patients with mental health problems. ${ }^{21}$

Despite the known benefits, continuity of care, as perceived by patients, is in decline in English general practice. ${ }^{22}$ There are many potential reasons behind this, including government policies that prioritise access, increasing numbers of GPs retiring early or working part time, ${ }^{23}$ and a lack of teaching on general practice subjects such as continuity of care in medical schools. ${ }^{24}$
Some doctors also believe continuity is only possible in single-GP practices or with fulltime GPs, and that continuity is more difficult or expensive. One additional reason for low levels of continuity is that working GPs find it difficult to quantify and, as Drucker described, measurement is necessary for management. ${ }^{25}$ If practices were able to measure and compare continuity rates for individual doctors, continuity might improve, as has been shown for other performance measures. ${ }^{26,27}$

There are a number of measures of continuity of care that have been used in general practice research. ${ }^{28,29}$ These include the Usual Provider of Care (UPC) index, ${ }^{30}$ which calculates the proportion of appointments that are with the most frequent provider; patient surveys including the GP Patient Survey; ${ }^{31}$ and several other measures that use appointment data, often from insurance records in the US and other countries to quantify continuity. 32,33 The UPC is the most simple and frequently used of these measures. The Royal College of General Practitioners provides a toolkit for measuring continuity within practices by calculating the UPC of a random sample of patients. ${ }^{34}$ These methods have the drawback of needing enough time for at least a minimum number of appointments (usually two) before they can be applied. They are, therefore, not practical methods of evaluating performance as part of regular audits to encourage and measure improvement in continuity of care.

Therefore a practical method was
K Sidaway-Lee, PhD, research fellow; D Pereira Gray OBE, Hon DSc, FRCP, FRCGP, FMedSci,

consultant; P Evans, MPhil, FRCGP, consultant, St Leonard's Research Practice and associate professor of general practice and primary care, University of Exeter Medical School, Exeter.

\section{Address for correspondence}

Kate Sidaway-Lee, St Leonard's Research Practice, Athelstan Road, Exeter EX1 1SB, UK
E-mail: K.sidaway-leedanhs.net

Submitted: 16 October 2018; Editor's response: 7 November 2018; final acceptance: 10 December 2018.

@British Journal of General Practice

This is the full-length article (published online 26 Feb 2019) of an abridged version published in print. Cite this version as: Br J Gen Pract 2019; DOl: https://doi.org/10.3399/bjgp19X701813 


\section{How this fits in}

Continuity of care in general practice benefits patients because it is associated with greater satisfaction, increased adherence to medical advice, better care for chronic illnesses, more evidencebased preventive care, less accident and emergency use, fewer hospital admissions, and lower mortality. Despite the evidence that continuity of care benefits GPs too, most general practices do not measure continuity regularly. A method has been developed for monthly measurement of continuity of care in a personal list in general practice, the St Leonard's Index of Continuity of Care (SLICC). This study demonstrates that a reasonable level of continuity can be achieved in a general practice where all GPs are part time.

developed for measuring continuity of care monthly in a general practice that uses personal lists. This method is called the St Leonard's Index of Continuity of Care (SLICC). This was first used with paper records at the practice in $1974^{16}$ and has since been used and refined. This study describes this method used in day-to-day general practice.

\section{METHOD}

This study makes use of regular appointment audit data from St Leonard's Practice in Exeter, UK. St Leonard's had, at the time of the study, seven GP partners and one salaried doctor, all part time. The practice is located near to the city centre in Exeter, England. The practice population had a mean 2010 Index of Multiple Deprivation (IMD) score of 17.1 compared with 21.67 for England (high being more deprived). ${ }^{35}$ The practice is a training practice and usually has one to two registrars working full or part time. There is also one sessional

\section{Box 1. How to calculate the SLICC}

1. Collect all GP face-to-face appointments for a patient group (for example, all patients on a particular doctor's personal list) over a specified time period into a spreadsheet. Include which doctor the appointment was with and which doctor's list the patient is on

2. Count which appointments were with the patients personal/registered GP.

3. Divide the number of appointments for the group that were with the personal GPs by the total number of appointments for the group.

4. Express as a percentage.

${ }^{a}$ The patient group would usually be a GP's personal list/list of registered patients as this allows comparison between doctors within a practice. The specified time period could be as short as a month, to allow regular repeated measurements that build up a picture of delivery of continuity of care in the longer term. SLICC = St Leonard's Index of Continuity of Care. doctor without a list. The practice uses the personal list system ${ }^{16}$ so that each patient has a named doctor who is one of the GP partners or a salaried doctor. This doctor takes responsibility for their list, and the practice actively encourages patients to book appointments with their own doctor where possible.

Data were collected from the practice database (SystmOne) as part of regular internal audits into appointment numbers, and length and proportion of appointments with personal doctor. Shortly after the end of each month, all appointments for that month were extracted from the database. Data extracted included arrival time, date, appointment duration, flags lincludes an indicator of telephone consultation), clinician, patient age, and their registered doctor at the practice ('usual carer'). Appointments, including home visits, were only counted if indicators showed they were not telephone appointments, if they were booked into appointment slots and lasted $>1$ minute. Appointments recorded as $>1$ hour are reset to 15 minutes as these are rarely real durations. A unique SystmOne ID was used to track individual patients (not NHS number). The ID number, age, and sex of all patients on each of the doctors' personal lists were also extracted each month. Deprivation was also checked using the $1 \mathrm{MD}^{36}$ from patients' postcodes. Data from 1 January 2016 to 31 December 2017 were used.

The practice population was compared with that of the UK's. ${ }^{37}$ For GP face-to-face appointments, the demographic breakdown of patients receiving these appointments was investigated. The annual consultation rate was calculated by dividing the number of appointments by the average population over the 2 years and then dividing by 2 (years).

Using Microsoft Excel, for each GP partner's personal list, the proportion of face-to-face appointments with the patients' personal doctor was calculated for each month; the SLICC (Box 1). This was also calculated over the 2 years and separately for patients aged $\geq 65$ years. Patients were also grouped into 5-year age bands, by sex, and by IMD quintiles. The proportion of a doctor's appointments that were with their own patients (own-patient ratio) was also investigated.

For each patient at the practice with two or more appointments, the UPC ${ }^{30}$ was calculated over the same 2 years. This was calculated by dividing the number of a patient's appointments with the doctor seen most frequently during the study period, by the patient's total number of appointments 
Figure 1. Age and sex distribution of patients registered at St Leonard's Practice during December 2016.

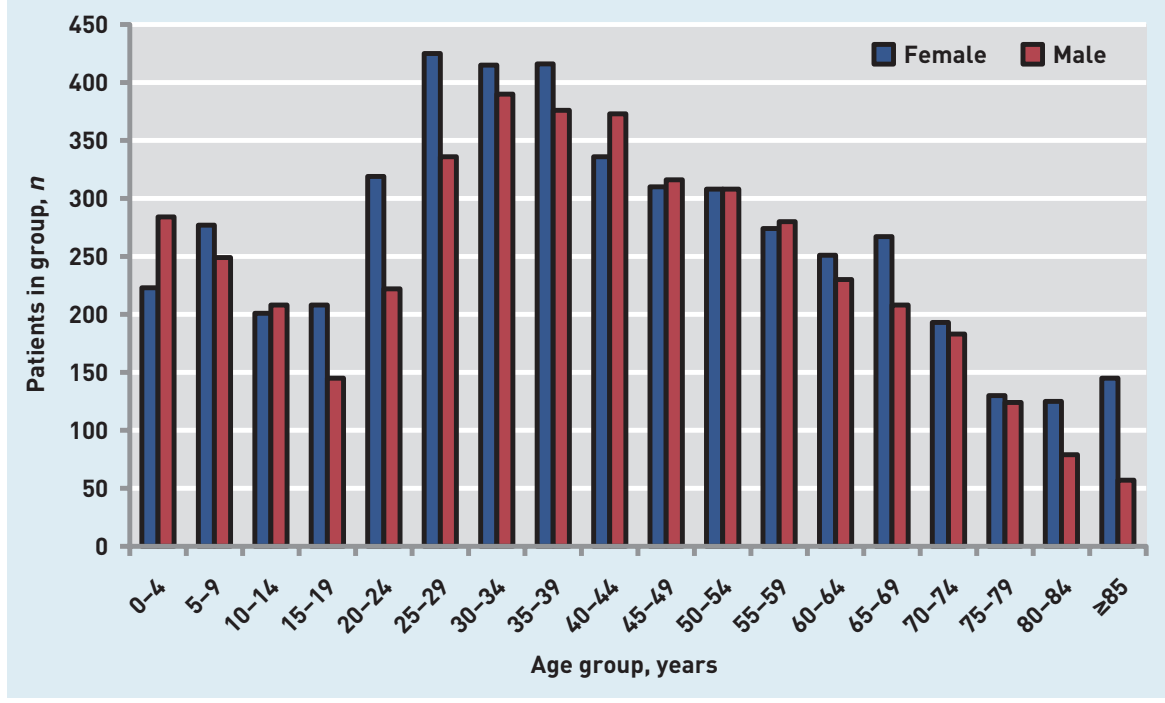

during the study period. Patients were categorised by the type of GP most seen lpersonal doctor, other practice doctor, locum, or registrar).

\section{RESULTS}

\section{Practice population}

The practice had 8823 registered patients of all ages in January 2016, and 9409 in December 2017, with a total of 10914 patients registered for at least 1 day of the study period. The age and sex distribution in the mid-point of the study, when there were 9189 patients (31 December 2016) is shown in Figure 1. Comparing Figure 1 with the population of the UK as a whole, ${ }^{37}$ the practice population had a higher proportion of adults aged 25-44 years (31.8\% versus $26.2 \%$ nationally) and slightly fewer patients aged $\geq 65$ years $(15.1 \%$ versus 18.0\%). The median registration in December 2016 was 6.6 years (interquartile range [IQR] $1.6-17.7$ years) and, in the 2 years of the study,
1610 patients left (including deaths) and 2429 joined (including births).

\section{Appointments}

In the 2-year study period, there were 35622 GP face-to-face appointments. The overall appointment rate was 1.96 appointments per patient per year. Patients with no face-to-face appointments numbered 2941 (26.9\%), with 1844 (16.9\%) having one appointment, 4833 (44.3\%) having two to seven appointments, and 1296 (11.9\%) having eight or more. Older patients as a group had more appointments, with $26.9 \%$ of appointments being for those $\geq 65$ years, despite them comprising only $15.3 \%$ of the practice population (Table 1), giving an annual appointment rate for patients aged $\geq 65$ years of 3.17 per patient.

A total of 28323 appointments (79.5\%) were with practice doctors, 6084 (17.1\%) with registrars, and 1398 (3.9\%) with locums. The mean recorded appointment length was

Table 1. Summary of patient numbers, appointments, the SLICC, and UPC for different groups of patients

\begin{tabular}{|c|c|c|c|c|c|}
\hline Patient group & Patients, $n(\%)$ & Appointments, $n(\%)$ & SLICC, $\%(95 \%$ Cl) & $P$-value & Mean UPC (N) \\
\hline All & $10914(100)$ & $35622(100)$ & $51.7(51.2$ to 52.2$)$ & - & 0.61 (6138) \\
\hline Aged $\geq 65$ years & 1673 (15.3) & $9574(26.9)$ & $65.0(64.0$ to 65.9$)$ & $<0.001$ & 0.69 (1305) \\
\hline Aged $<65$ years & 9241 (84.7) & $26048(73.1)$ & $46.8(46.2$ to 47.4$)$ & & $0.59(4824)$ \\
\hline$\geq 8$ appointments in 2 years & 1296 (11.9) & $15866(44.5)$ & $59.4(58.6$ to 60.1$)$ & $<0.001$ & $0.61(1296)$ \\
\hline$<8$ appointments in 2 years & $9618(88.1)$ & $19756(55.5)$ & 45.5 (44.8 to 46.2$)$ & & 0.61 (4833) \\
\hline Most deprived 2 national quintiles & 3753 (34.4) & $13330(37.4)$ & $54.0(53.1$ to 54.8$)$ & 0.001 & 0.62 (2113) \\
\hline Least deprived 2 national quintiles & 4049 (37.1) & 12895 (36.2) & $52.0(51.1$ to 52.8$)$ & & $0.62(2351)$ \\
\hline Female & $5763(52.8)$ & $21156(59.4)$ & $50.9(50.2$ to 51.6$)$ & $<0.001$ & 0.60 (3578) \\
\hline Male & $5151(47.2)$ & $14466(40.6)$ & $52.8(52.0$ to 53.7$)$ & & $0.63(2551)$ \\
\hline
\end{tabular}

SLICC = St Leonard's Index of Continuity of Care. UPC = Usual Provider of Care 


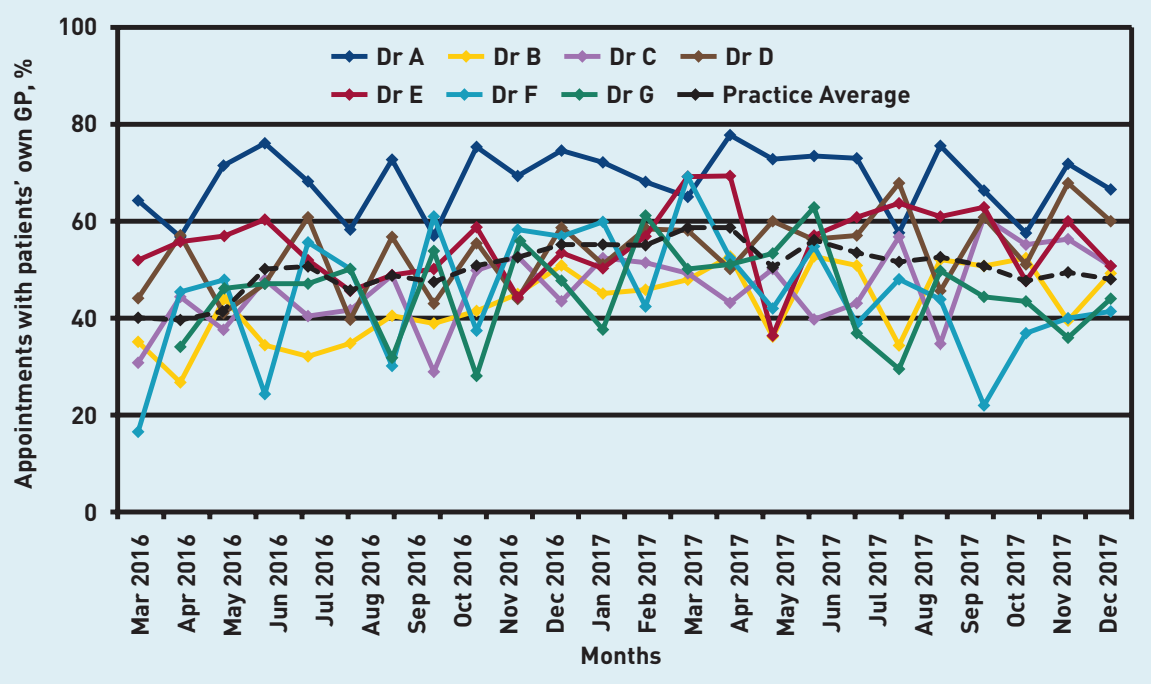

Figure 2. Patient consultations with own GP. The St Leonard's Index of Continuity of Care (SLICC), which is the percentage of appointments provided for patients on a GP partner's list that were with that GP, each month. The practice average is the percentage of all appointments in that month that were with the patient's own GP.

Figure 3. The SLICC (percentage of appointments that are with the personal GPJ by age group. Error bars represent $95 \%$ Cls. SLICC = St Leonard's Index of Continuity of Care.
16.6 minutes (standard deviation [SD] 8.6); when locums and registrars are excluded this is 15.9 minutes (SD 8.3)

\section{GP personal list continuity}

Overall using the SLICC it was found that $51.7 \%(95 \%$ confidence interval $[\mathrm{Cl}]=51.2$ to $52.2 \%$ ) of appointments at the practice were with the patients' personal doctor. The proportion of patients on each list seeing their own doctor each month is shown in Figure 2. There was a large variation between months and between doctors, from $<30 \%$ in months where a doctor was on leave, to $>70 \%$ for one list. The list with the highest SLICC score was the list with a higher proportion of older people ( $24.4 \%$ aged $\geq 65$ years) and also that of the longest-serving GP.

For those patients aged $\geq 65$ years, the SLICC-calculated proportion of patient

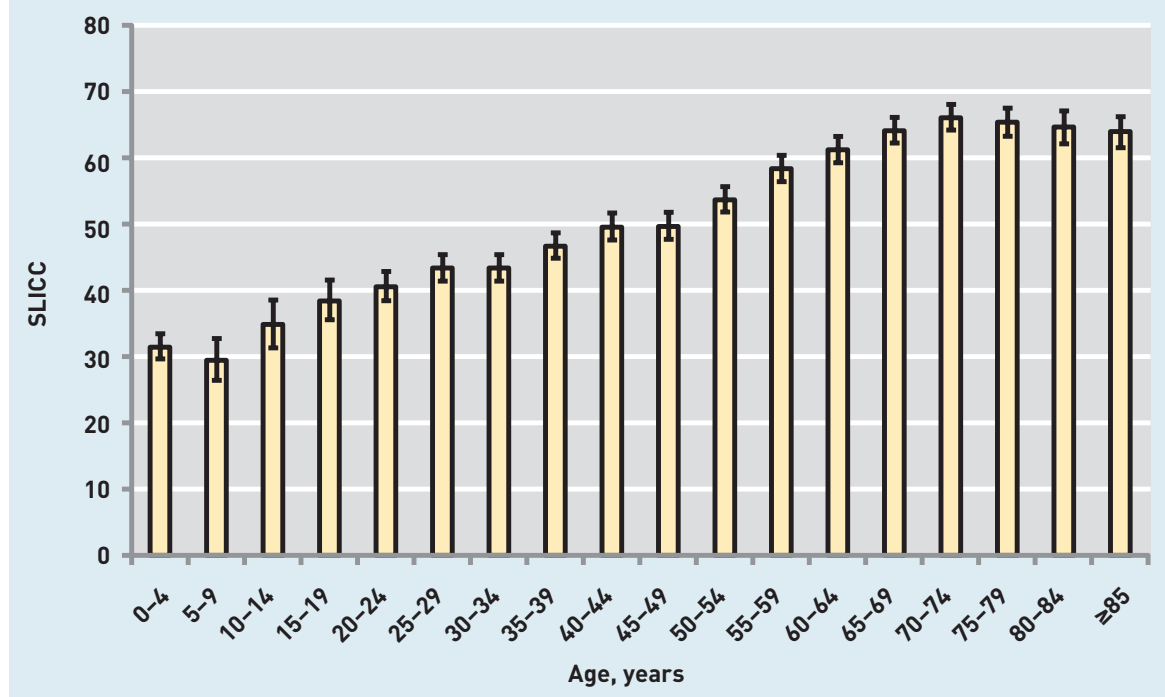

appointments with a patient's personal doctor was $65.0 \%(95 \% \mathrm{Cl}=64.0$ to $65.9 \%)$ The proportion of appointments that were with the personal GP for each 5-year age band is shown in Figure 3. Older age groups have a higher SLICC, peaking in the 70-74 years age group. More deprived patients, males, and patients with over seven appointments had a higher SLICC (Table 1). Figure 4 shows the proportion of all of each doctor's appointments that were with their own patients lown-patient ratio). Overall, this proportion was $69.4 \%$ of all appointments with doctors who have personal lists. This was higher than the SLICC, as appointments with registrars, the sessional doctor, and locums are not included.

\section{Individual patient continuity using the UPC}

For the 6138 patients at the practice with at least two appointments over the study period the mean UPC was 0.61 (SD 0.23).

For $3243(52.8 \%)$ patients, the doctor seen most frequently was also the personal doctor. For 509 (8.3\%) this was another practice doctor, 477 (7.8\%) a registrar, and $19(0.3 \%)$ a locum. For 1890 (30.8\%) patients there were two or more doctors who were seen equally frequently, and for 1190 patients $162.9 \%$ of those with more than one usual provider) this included the personal doctor. Therefore 4433 (72.2\%) patients had their personal GP as either their sole or shared usual provider. People aged $\geq 65$ years had a significantly $(P<0.001)$ higher UPC (mean 0.69, SD 0.22), than those aged $<65$ years (mean 0.59 , SD 0.23).

\section{DISCUSSION}

\section{Summary}

Overall, using the SLICC, $51.7 \%$ of faceto-face GP appointments were with the personal doctor, despite a large number of appointments with registrars and all GPs being part-time. For those aged $\geq 65$ years, $64.9 \%$ of face-to-face GP appointments were with the personal doctor. When using the UPC for comparison, in the majority of patients the most commonly seen GP was their personal doctor.

\section{Strengths and limitations}

This study was carried out in a general practice with all GPs at the practice working part time. The method and focus on continuity could therefore be easily replicated elsewhere ffurther information, including a template Microsoft Excel file to assist with this, is available from the authors). 
Figure 4. GP appointments with own-list patients. The own-patient ratio is the percentage of appointments with a specific GP partner that were with patients on their own personal list. The practice average uses the number of appointments that were with GPs who have lists as the denominator.

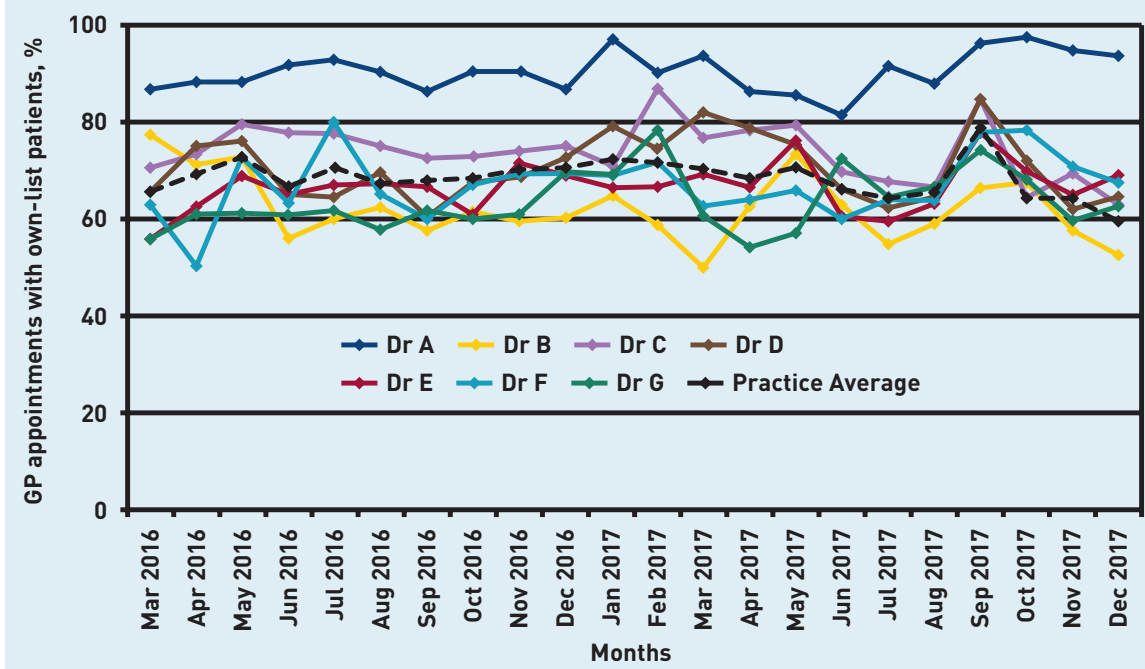

\section{Box 2. Comparison of the UPC index and the SLICC}

\begin{tabular}{|c|c|c|}
\hline & UPC & SLICC \\
\hline Developed by & Academic unit & Service general practice \\
\hline Intended use & Continuity of care research & $\begin{array}{l}\text { Regular continuity measurement in } \\
\text { day-to-day general practice }\end{array}$ \\
\hline Unit of measurement & Patient & Appointment \\
\hline $\begin{array}{l}\text { Specificity to personal } \\
\text { doctor }\end{array}$ & $\begin{array}{l}\text { Generally used so that the } \\
\text { most frequent provider is } \\
\text { the 'usual' doctor. This may } \\
\text { be another doctor, for } \\
\text { example, a locum or trainee }\end{array}$ & $\begin{array}{l}\text { Registered personal doctor only. } \\
\text { This is a requirement }\end{array}$ \\
\hline Most-seen GP & $\begin{array}{l}\text { UPC can score a doctor as } \\
\text { usual provider when they } \\
\text { provide a minority of the } \\
\text { appointments, just more } \\
\text { than other doctors. More } \\
\text { than one doctor can be the } \\
\text { most-seen provider }\end{array}$ & $\begin{array}{l}\text { Gives a percentage of appointments } \\
\text { that are with the personal doctor }\end{array}$ \\
\hline Range of scores & $\begin{array}{l}\text { A score of } 0 \text { is impossible. } \\
\text { Consistently higher than SLICC }\end{array}$ & Can be $0-100 \%$ \\
\hline Timeframe & $\begin{array}{l}\text { At least two and ideally more } \\
\text { appointments required. This } \\
\text { can take several years in } \\
\text { relatively healthy patients }\end{array}$ & A measure for monthly audits \\
\hline Selection bias & $\begin{array}{l}\text { Includes only patients with } \\
\text { a minimum number of } \\
\text { appointments (usually two) }\end{array}$ & Includes all appointments \\
\hline $\begin{array}{l}\text { Ability to take into } \\
\text { account team continuity }\end{array}$ & No, individual provider & No, individual provider \\
\hline $\begin{array}{l}\text { Ability to compare } \\
\text { patient groups }\end{array}$ & $\begin{array}{l}\text { Yes, although patients with } \\
\text { few appointments are often } \\
\text { excluded }\end{array}$ & $\begin{array}{l}\text { Yes, especially between GP lists } \\
\text { and including infrequent attenders }\end{array}$ \\
\hline $\begin{array}{l}\text { Ability to obtain scores } \\
\text { for individual patients }\end{array}$ & Yes & No \\
\hline Ease of use & $\begin{array}{l}\text { Simple proportion easy to } \\
\text { calculate and interpret }\end{array}$ & $\begin{array}{l}\text { Simple proportion/percentage } \\
\text { easy to calculate and interpret }\end{array}$ \\
\hline
\end{tabular}

$S L I C C=$ St Leonard's Index of Continuity of Care. UPC = usual provider of care 
The data rely on GPs accurately recording appointments. However, as these audits are carried out within the practice, the data are checked at the time of extraction, ensuring that the majority of appointment types are correct and that few are missed out. GPs know that these audits take place and are used for internal workload monitoring, an incentive for accurate recording. The measurement of appointment duration is subject to additional error as it depends on the GP opening a patient record at the start of a consultation, then closing it at the end as in other studies. ${ }^{38}$

Patients can choose their personal doctor and occasionally move between GP's lists, which may affect the counting of appointments with the personal doctor in the month of switchover. Patients also choose to have appointments with another $\mathrm{GP}$, particularly female patients with a male personal doctor requesting consultations with a female doctor. This may be why male patients have a statistically significantly higher SLICC

As the study was carried out in a single practice, the results may be different in other areas with different practice populations. The SLICC has not yet been applied to other practices' data although this is planned and it has been used both with SystmOne and with VAMP/Vision practice software at St Leonard's, therefore it should be transferable.

The SLICC measure described here has some major advantages for GPs (Box 2). It is a simple measure and, as it uses the entire registered list, it is applicable to short periods of time and includes patients who only have one appointment, unlike the UPC which is predicated on patients with more appointments. In addition, the UPC has a floor effect as it is not possible to have a value of zero, because the doctor it refers to is the doctor most frequently seen. Indeed, when there are only two appointments, the lowest value possible is 0.5 . With the SLICC a value of $0 \%$ is possible and occurs for a doctor's list in months when they are on long-term leave. The UPC can also take a locum or registrar as the usual doctor: $8.1 \%$ of the time in this study.

\section{Comparison with existing literature}

Continuity of care is in decline in English general practice. ${ }^{22}$ To manage and improve continuity of care, GPs need to be able to measure it effectively. The UPC, used in research ${ }^{14,28-30,33}$ and in the RCGP toolkit, ${ }^{34}$ measures continuity at a patient level and requires a certain number of consultations, excluding patients who consult less frequently. It also usually requires a longer time period, whereas when using the SLICC it is possible to measure continuity on a monthly basis, as well as to make comparisons between individual doctors (Box 2 shows comparison of methods).

The requirement, in England, for a named doctor, introduced for patients aged $\geq 75$ years in 2014 and for all patients in $2015,{ }^{39}$ had little effect on continuity of care or patient outcomes, at least over 9 months. ${ }^{40}$ However, if, as intended, personal lists ${ }^{16}$ are used effectively by practices and continuity is actively measured, there may be more of an impact. The SLICC could be applied to the named doctor if there is no personal list.

Continuity has benefits for patients, doctors, and health systems. ${ }^{2-15}$ Comparing the St Leonard's appointment rate of 1.96 face-to-face GP appointments per patient per year to the national average consultation rate of $3.18^{41}$ equates to 11057 fewer appointments each year. Although the demographic of the practice population ${ }^{42}$ and the length of appointments offered could also contribute to this, the focus on continuity of care at the practice may also be having an effect.

\section{Implications for practice}

Having 52\% of appointments with a personal doctor may seem low at first glance; however, with an average of two face-to-face appointments per patient per year and a median length of registration of 6.6 years, a patient will have around six or seven appointments of over 15 minutes each with their own doctor. This means 1.5 hours in which the doctor and patient can get to know each other. ${ }^{43}$ This is likely to be even longer for older patients, for whom continuity is particularly important, ${ }^{44}$ as they have both higher continuity levels and more appointments. This method provides working GPs with a simple way to track GP continuity of care monthly. As continuity of care has multiple benefits, it is hoped that this system will be adopted in many practices.

The authors would like to thank the doctors, staff, and patients of St Leonard's Practice, Exeter, UK.

\section{Discuss this article}

Contribute and read comments about this article: bjgp.org/letters 


\section{REFERENCES}

1. Sweeney KG, Pereira Gray D. Patients who do not receive continuity of care from their general practitioner - are they a vulnerable group? Br J Gen Pract 1995; 45(392): 133-135.

2. Hjortdahl P. Continuity of care: general practitioners' knowledge about, and sense of responsibility towards their patients. Fam Pract 1992; 9(1): 3-8.

3. Mainous AG 3rd, Baker R, Love MM, et al. Continuity of care and trust in one's physician: evidence from primary care in the United States and the United Kingdom. Fam Med 2001; 33(1): 22-27.

4. Ridd M, Shaw A, Salisbury C. 'Two sides of the coin' - the value of personal continuity to GPs: a qualitative interview study. Fam Pract 2006; 23(4): 461-468.

5. British Medical Association. National survey of GPS: the future of general practice 2015. 2018. http://bma.org.uk/working-for-change/negotiating-for-theprofession/bma-general-practitioners-committee/surveys/future-of-generalpractice laccessed 28 Jan 2019).

6. De Maeseneer JM, De Prins L, Gosset C, Heyerick J. Provider continuity in family medicine: does it make a difference for total health care costs? Ann Fam Med 2003; 1(3): 144-148.

7. Hjortdahl P, Laerum E. Continuity of care in general practice: effect on patient satisfaction. BMJ 1992; 304(6837): 1287-1290.

8. Adler R, Vasiliadis A, Bickell N. The relationship between continuity and patient satisfaction: a systematic review. Fam Pract 2010; 27(2): 171-178.

9. Chen $\mathrm{CC}$, Tseng $\mathrm{CH}$, Cheng $\mathrm{CH}$. Continuity of care, medication adherence, and health care outcomes among patients with newly diagnosed type 2 diabetes: a longitudinal analysis. Med Care 2013; 51(3): 231-237.

10. Warren JR, Falster MO, Tran B, Jorm L. Association of continuity of primary care and statin adherence. PLoS One 2015; 10(10): e0140008.

11. O'Malley AS, Mandelblatt J, Gold K, et al. Continuity of care and the use of breast and cervical cancer screening services in a multiethnic community. Arch Intern Med 1997; 157(13): 1462-1470.

12. Christakis DA, Mell L, Wright JA, et al. The association between greater continuity of care and timely measles-mumps-rubella vaccination. Am J Public Health 2000; 90(6): 962-965.

13. Hansen $\mathrm{AH}$, Halvorsen PA, Aaraas IJ, Førde OH. Continuity of GP care is related to reduced specialist healthcare use: a cross-sectional study. Br J Gen Pract 2013; DOI: https://doi.org/10.3399/bjgp13X669202.

14. Barker I, Steventon A, Deeny SR. Association between continuity of care in general practice and hospital admissions for ambulatory care sensitive conditions: cross sectional study of routinely collected, person level data. BMJ 2017; 356: j84.

15. Pereira Gray D, Sidaway-Lee K, Thorne A, et al. Continuity of care with doctors - a matter of life and death? A systematic review of continuity of care and mortality. BMJ Open 2018; 8(6): e021161.

16. Pereira Gray DJ. The key to personal care. J R Coll Gen Pract 1979; 29(208): 666-678.

17. Roland M, Mayor V, Morris R. Factors associated with achieving continuity of care. J R Coll Gen Pract, 1986; 36(384): 101-104.

18. Freeman GK, Richards SC. How much personal care in four group practices? BMJ 1990; 301(6759): 1028-1030.

19. Baker R, Streatfield J. What type of practice do patients prefer? Exploration of practice characteristics influencing patient satisfaction. Br J Gen Pract 1995; 45(401): 654-659.

20. Risi L, Bhatti N, Cockman P, et al. Micro-teams for better continuity in Tower Hamlets: we have a problem but we're working on a promising solution! $\mathrm{Br} J$ Gen Pract 2015; DOI: https://doi.org/10.3399/bjgp15X687025.

21. Hill AP, Freeman GK. Promoting continuity of care in general practice. RCGP Policy Paper. London: Royal College of General Practitioners, 2011.

22. Levene LS, Baker R, Walker N, et al. Predicting declines in perceived relationship continuity using practice deprivation scores: a longitudinal study in primary care. Br J Gen Pract. 2018; DOI: https://doi.org/10.3399/bjgp18X696209.
23. Fletcher E, Abel GA, Anderson R, et al. Quitting patient care and career break intentions among general practitioners in South West England: findings of a census survey of general practitioners. BMJ Open 2017; 7(4): e015853.

24. Harding A, Rosenthal J, Al-Seaidy M, et al. Provision of medical student teaching in UK general practices: a cross-sectional questionnaire study. $\mathrm{Br} \mathrm{J}$ Gen Pract 2015; DOI: https://doi.org/10.3399/bjgp15X685321.

25. Drucker P. The practice of management. New York, NY: Harper Collins, 1954.

26. Pereira Gray D. Primary care and the public health, Harben Lecture 1994. Health \& Hygiene 1995; 16: 49-62.

27. Kontopantelis E, Reeves D, Valderas JM, et al. Recorded quality of primary care for patients with diabetes in England before and after the introduction of a financial incentive scheme: a longitudinal observational study. BMJ Qual Saf 2013; 22(1): 53-64.

28. Jee $\mathrm{SH}, \mathrm{Cabana} \mathrm{MD}$. Indices for continuity of care: a systematic review of the literature. Med Care Res Rev 2006; 63(2): 158-188.

29. Salisbury C, Sampson F, Ridd M, Montgomery AA. How should continuity of care in primary health care be assessed? Br J Gen Pract 2009; DOI: https://doi. org/10.3399/bjgp09X420257.

30. Breslau N, Haug MR. Service delivery structure and continuity of care: a case study of a pediatric practice in process of reorganization. J Health Soc Behav 1976; 17(4): 339-352

31. Ipsos Mori 2018. GP Patient Survey. https://unw.gp-patient.co.uk/Files/ Questionnaire2018.pdf (accessed 28 Jan 2019).

32. Pollack CE, Hussey PS, Rudin RS, et al. Measuring care continuity: a comparison of claims-based methods. Med Care 2016; 54(5): e30-e34.

33. Van Walraven SC, Oake N, Jennings A, Forester AJ. The association between continuity of care and outcomes: a systematic review and critical review. J Eval Clin Pract 2010; 16(5): 947-956.

34. Royal College of General Practitioners. RCGP continuity toolkit. https://www. rcgp.org.uk/-/media/Files/Policy/A-Z-policy/RCGP-Continuity-of-Care-Toolkit. ashx?la=en (accessed 28 Jan 2019).

35. White ES, Pereira Gray D, Langley P, Evans PH. Fifty years of longitudinal continuity in general practice: a retrospective observational study. Fam Pract 2016; 33(2): 148-153

36. Ministry of Housing, Communities and Local Government. English indices of deprivation 2015. 2015. https://mww.gov.uk/government/statistics/englishindices-of-deprivation-2015 (accessed 28 Jan 2019).

37. Office for National Statistics. Estimates of the population for the UK, England and Wales, Scotland and Northern Ireland. 2018. https://uww.ons.gov.uk/ peoplepopulationandcommunity/populationandmigration/populationestimates/ datasets/populationestimatesforukenglandandwalesscotlandandnorthernireland (accessed 28 Jan 2019).

38. Stevens S, Bankhead C, Mukhtar T, et al. Patient-level and practice-level factors associated with consultation duration: a cross-sectional analysis of over one million consultations in English primary care. BMJ Open 2017; 7(11): e018261.

39. NHS England. Standard General Medical Services contract variation notice - April 2015. 2015. https://www.england.nhs.uk/commissioning/wp-content/ uploads/sites/12/2015/07/gms-variation-note-04-15.pdf (accessed 28 Jan 2019).

40. Barker I, Lloyd T, Steventon A. Effect of a national requirement to introduce named accountable general practitioners for patients aged 75 or older in England: regression discontinuity analysis of general practice utilisation and continuity of care. BMJ Open 2016; 6(9): e011422.

41. Hobbs FDR, Bankhead C, Mukhtar T, et al. Clinical workload in UK primary care: a retrospective analysis of 100 million consultations in England, 2007-14. Lancet 2016; 387(10035): 2323-2330

42. Mukhtar TK, Bankhead C, Stevens S, et al. Factors associated with consultation rates in general practice in England, 2013-2014: a cross-sectional study. $\mathrm{Br} \mathrm{J}$ Gen Pract 2018; DOI: https://doi.org/10.3399/bjgp18X695981.

43. Pereira Gray D. Forty-seven minutes a year for the patient. Br J Gen Pract 1998; 48(437): 1816-1817.

44. Kearley KE, Freeman GK, Heath A. An exploration of the value of the personal doctor-patient relationship in general practice. Br J Gen Pract 2001; 51(470): 712-718. 